\title{
Contagion between liquid and illiquid assets during the financial crisis: evidence from the US credit derivative market
}

\author{
Jungmu Kim \\ Yeungnam University, Gyeongsan, Republic of Korea, and \\ Yuen Jung Park \\ Hallym University, Chuncheon, Republic of Korea
}

\begin{abstract}
This study aims to investigate the existence of contagion between liquid and illiquid assets in the credit default swap (CDS) market around the recent financial crisis. The authors perform analyses based on vector autoregression model and the dynamic conditional correlation model. The estimation of vector autoregression models reveals that changes in liquid CDS (LCDS) spreads lead to changes in illiquid CDS spreads at least one week ahead during the financial crisis period, whereas the leading direction is reversed during the post-crisis period. Moreover, the results are robust after controlling for structural variables which are proven as determinants of CDS spreads and are empirically supported. This study interprets that information was incorporated first into the LCDSs because of the flight-to-liquidity during the recent crisis period but there is a default contagion effect by reflecting illiquidity-induced credit risk after the crisis. Finally, the dynamic conditional correlation analysis also confirms the main results.
\end{abstract}

Keywords Credit default swap, Contagion, Dynamic conditional correlation, Flight-to-liquidity, Granger causality

Paper type Research paper

\section{Introduction}

Understanding and managing the risk of financial contagion are of importance because a whole of the financial system is likely to collapse when contagion effects are severe. Financial contagion typically refers to negative shock transmission from one system to another; a narrow definition of the system can be one asset or an asset class and a broad definition can be a country or an economic system such as the European Union. Recently, experiencing the recent financial crisis and the European debt crisis from 2007 to 2010, the participants of global financial markets realized that they had underestimated the contagion risk. The impact of contagion was more than they expected. This shock has led many studies to pay attention to contagion risk

(C) Jungmu Kim and Yeun Jung Park. Published in Journal of Derivatives and Quantitative Studies: 선물연구. Published by Emerald Publishing Limited. This article is published under the Creative Commons Attribution (CC BY 4.0) licence. Anyone may reproduce, distribute, translate and create derivative works of this article (for both commercial and non-commercial purposes), subject to full attribution to the original publication and authors. The full terms of this licence may be seen at http:// creativecommons.org/licences/by/4.0/legalcode

JEL classification - G12, G14

Funding: This research was supported by Hallym University Research Fund, HRF-202008-008. 
JDQS 28,3

In this study, we examine whether a contagion effect exists between the liquid and illiquid credit default swaps (CDSs) around the recent global financial crisis. By doing so, we investigate how liquidity affects contagion in times of crisis. Liquidity squeeze is typically mentioned as one of the reasons that have magnified the global financial crisis. In addition, CDSs are regarded as a distressed asset because of the subprime mortgage defaults during the recent crisis. Thus, the analysis exploring whether there exist the flight-to-liquidity phenomenon and contagion effect between liquid CDSs (LCDSs) and illiquid CDSs (ICDSs) can be helpful in understanding the role of liquidity that plays in negative shock transmission or contagion in times of crisis.

Methodologically, we borrow Longstaff (2010)'s idea, which estimated vector autoregression (VAR) models to investigate the existence of contagion between assets. Even though a variety of methods has been used to test the existence of contagion in the finance literature, we choose the VAR method for the following reasons. First, the contagion test by the VAR model is based on a theory of finance. Testing contagion is so challenging that there has not been a consensus on how to define and estimate contagion. We estimate, if any, the lead-lag relationship between two groups. In the view of the efficient market hypothesis, if the market is efficient, there should not exist any lead-lag relationship because all information available is instantly and fully reflected in asset prices. Putting differently, a lead-lag relation can be evidence of financial contagion. Thus, our approach is intuitive and easy to understand.

Second, our approach using the VAR model can provide implications about the direction of contagion. A strand of research has tested the existence of contagion according to the definition that contagion results in an excessive increase in interdependence among assets. However, such an approach is silent in the direction of the contagion. For example, many papers including Celik (2012), Pontines and Siregar (2009), Naoui et al. (2010) use the dynamic conditional correlation (DCC) method to provide evidence on the existence of contagion. Some researchers including (Rodriguez, 2007; Cheng et al., 2012; Aloui et al., 2011) use a copula function approach to estimate contagion impact. While the DCC and copula methods are effective to estimate interdependence, the question about the direction of the contagion still remains unproven. Contrarily, the VAR approach allows us to reach a conclusion about the direction of contagion as well as the existence of contagion. In particular, the Granger causality test that we conduct is known as one of the best methods to test the nexus of cause and effect.

To study financial contagion during the crisis, we focus on the CDS market for several reasons. First, the CDS market, the playground of this study, is an almost ideal laboratory to study contagion phenomena during crises. CDSs are typically pointed out as a reason for the amplification or contagion of the recent financial crisis (Stulz, 2010; Dieckmann and Plank, 2012; Terzi and Uluçay, 2011). While a variety of financial markets such as stock, bonds and options were significantly affected during the crisis, the contagion within the CDS market, the so-called Big-Bang, was an unprecedented phenomenon.

Second, while we narrow down our scope on the CDS market for the purpose of this study, our conclusion is not derived from a narrow scope of assets because we cover all corporate CDSs (about 500 companies) issued in the USA. Moreover, in terms of market size, the CDS market is not ignorable. At the time of the recent financial crisis around 2008, the CDS market was the most rapidly growing market. According to the Bank for International Settlements, the total notional amount of the CDSs outstanding was $\$ 41 \mathrm{tn}$ at the end of 2008 (Stulz, 2010). Thus, the impact of contagion within such a huge market is of fundamental significance. 
The remainder of this paper proceeds as follows. Section 2 summarizes the background literature. Section 3 introduces the analytical methodology. Section 4 describes the data and presents the empirical results from Granger causality and VAR analysis. Section 5 presents the result of the alternative contagion model. Finally, Section 6 concludes our empirical results and remarks.

Contagion
between liquid
and illiquid
assets

Our research is associated with three areas of finance literature. First, our investigation is associated with studying the financial contagion. Following Bae et al. (2003), contagion is not just the cross-market linkage, but the phenomenon of outstanding increase in the crossmarket linkage when shock occurs in a financial market. Financial contagion has attracted much attention for a long time because the currency crisis of Asia in the late 1990s and numerous studies generally focused on the macroeconomic perspective of the contagion. For example, Dornbusch et al. (2000) show that the financial crisis of one country spreads to other countries through international trade and associations of the financial system. Eichengreen et al. (1996) report that the contagion of crisis occurs more easily in a country with a stronger trade linkage with other countries. Cheung et al. (2009) insist that the main sources of contagion are the international finance system, competitive trade structure, economic and political linkage and herding behavior by information asymmetry.

On the other hand, recent studies concentrate on the contagion between financial assets markets (Longstaff, 2010; Rösch and Kaserer, 2013; Cifuentes et al., 2005; Hegde and Paliwal, 2011; Jacoby et al., 2009). Longstaff (2010) documents that returns of asset-backed collateralized debt obligations (CDOs), as distressed assets, predict returns and yields of stock and bond, known as more liquid assets than CDOs, during the global financial crisis. Also, the paper provides evidence that contagion was spilled over through the liquidity channel. Rösch and Kaserer (2013) show that market liquidity risk induces the illiquidity transmission across markets and thus liquidity commonality can be a driving force of financial contagion. Cifuentes et al. (2005) conclude that liquidity buffers on institutions can be as effective as capital buffers in preventing contagious failures. Hegde and Paliwal (2011) suggest that models of financial crisis and contagion forecast that an economic crisis may spread to a crisis of market liquidity.

Our work is also associated with the literature on the flight-to-liquidity. Vayanos (2004) states that the concept of the flight-to-liquidity indicates that investors abruptly and strongly prefer holding liquid assets. The paper shows that, through analysis for liquid/ illiquid asset pairs, the differences in premiums between liquid and illiquid assets are substantially large during the extreme market events. Moreover, Longstaff (2002) insists that when investors' fear about the future economic circumstances increases, the more liquid treasury bonds are preferred, resulting in the rise of liquidity premium.

Finally, our study is also associated with the below literature on the importance of liquidity in pricing CDS. Bongaerts et al. (2011) document that the seller of CDS requires the premium on the expected liquidity but CDS market participants may not price liquidity risk. In contrast, Tang and Yan (2010) analyze the liquidity effect on CDS spreads and find that there exists a significant liquidity premium and the liquidity risk is positively priced beyond liquidity property in CDS spreads. Han and Kumar (2013) report that liquidity risk dominates firm-specific credit risk in explaining CDS price changes, irrelevantly to market conditions. Meanwhile, Hilscher et al. (2015) insist that liquidity-based trading mainly occurs in the CDS market while information-based trading mainly occurs in the stock market because transaction costs are higher in the CDS market. 
JDQS 28,3

Our study adds the following contributions to the existing literature. First, previous studies generally focused on the contagions between countries or between the financial assets markets (Guo et al., 2011; Kim et al., 2016). However, there are a few studies on contagion within an asset class. This study explores the contagion effect within a class of credit asset markets, not the contagion effect among two or more classes of assets markets. Second, while Longstaff (2010) focuses on the subprime-mortgage crisis and finds that the information of illiquid asset is transmitted to the more liquid assets during the crisis period, our research discovers that the less liquid assets predicted the future movement of moreliquid assets during the post-crisis period. In this regard, we should remind the statement, pointed out by Longstaff (2010)'s footnote, that credit-risk-induced illiquidity may be an important factor during the crisis period as investors avoid taking positions in mortgagerelated contracts whereas illiquidity-induced credit risk may be a critical factor during the post-crisis period as major financial institutions confronted default because they can not liquidate positions and collateralize their liabilities. Our results support this statement by suggesting the evidence of contagion within one credit asset market, not the contagion among two or more classes of assets markets. Finally, a noticeable distinction of our study is that our methodology can examine the role of flight-to-liquidity in the CDS market. We construct LCDS and ICDS spreads using CDS depth data and examine the existence and direction of contagion between them. Thereby, we can provide implications on the contagion in the CDS market and the role of flight-to-liquidity in the contagion.

\section{Methodology}

To measure a representative CDS spread of firms having high/low CDS liquidity, we calculate a simple average of CDS spreads categorized within the highest/lowest ranking after sorting individual firms based on their CDS liquidity. Specifically, every Wednesday, we sort the firms into five groups on a basis of "depth" which is the number of quotes of CDS sellers and take the average of their CDS spreads across firms within the highest/lowest quintile group. We assume that the average spread is the proxy for spreads of the "representative CDS" with high/low liquidity. We define the average CDS spread of low liquidity portfolio as ICDS and the averaged CDS spread of high liquidity portfolio as LCDS. With these proxy spreads of representative firms, we investigate the role of liquidity that plays in financial contagion in the credit derivative market.

We begin by first examining whether the global financial crisis increased cross-linkage between LCDS and ICDS. We conjecture that the price of the LCDS leads the price of the ICDSs because of flight-to-liquidity behavior during the global financial crisis. Thus we examine the following two hypotheses as follows:

\section{H1. LCDS Granger causes ICDS.}

H2. LCDS has forecasting power for ICDS.

To explore the association between the LCDS and the ICDS, we estimate the following VAR specification [1]:

$$
\Delta I C D S_{t}=\alpha+\sum_{k=1}^{4} \beta_{k} \Delta I C D S_{t-k}+\sum_{k=1}^{4} \gamma_{k} \Delta L C D S_{t-k}+\varepsilon_{t}
$$

We examine the coefficients of change in LCDS to capture the information on Grandercausality from the VAR model. We perform $F$-test regarding the null hypothesis that all $\gamma_{k} \mathrm{~S}$ 
are zero in equation (1). Here, the $F$-statistics are the Wald statistics for the joint hypothesis, $\gamma_{1}=\gamma_{2}=\gamma_{3}=\gamma_{4}=0$. If we cannot reject the null hypothesis, we can draw the conclusion that LCDS Granger causes ICDS. The below is the Chi-square formula computed for the Grander-causality test:

$$
\chi^{2}=\frac{(r S S E-u S S E) / p}{u S S E /(T-2 q-1)}
$$

where $r S S E$ is the sum of squares because of the error with the restriction that all $\gamma_{k}$ s are zero, $u S S E$ is the unrestricted sum of squares because of error, $T$ is the total observation number and $q$ is the lag number of the VAR model.

Turning to the question of whether the various firms of CDS markets behaved similarly around the onset of the crisis, we test hypotheses and VAR system as follows. We assume that there is a contagion effect within the CDS market around the global financial crisis because the illiquidity of the CDS market may deteriorate the credit quality of the most CDSs:

H3. ICDS Granger causes $L C D S$.

H4. ICDS has forecasting power for $L C D S$.

$$
\Delta L C D S_{t}=\alpha+\sum_{k=1}^{4} \beta_{k} \Delta L C D S_{t-k}+\sum_{k=1}^{4} \gamma_{k} \Delta I C D S_{t-k}+\varepsilon_{t}
$$

We check the coefficients of change in ICDS to obtain the information on Grander-causality. We conduct $F$-test concerning the null hypothesis that all $\gamma_{k}$ s are zero in equation (3). If we cannot reject the null hypothesis, we can verify that ICDS Granger causes $L C D S$.

Meanwhile, many studies report that theoretical variables such as leverage ratio, asset volatility and risk-free rate are critical determinants in explaining the changes of CDS spreads (Di Cesare and Guazzarotti, 2010; Ericsson et al., 2009; Galil et al., 2014; Greatrex, 2008; Kim et al., 2017). Thus, we need to test whether flight-to-liquidity behaviors or contagion effects remain after controlling for the determinants of default probability, the socalled structural variables (Berndt et al., 2008; Doshi et al., 2013; Eom et al., 2004; Merton, 1974). Related hypotheses and their VAR specifications are as follows:

H5. LCDS has forecasting power for ICDS after controlling for structural variables.

H6. ICDS has forecasting power for $L C D S$ after controlling for structural variables.

$$
\begin{aligned}
& \Delta I C D S_{t}=\alpha+\sum_{k=1}^{4} \beta_{\mathrm{k}} \Delta I C D S_{t-k}+\sum_{k=1}^{4} \gamma_{\mathrm{k}} \Delta L C D S_{t-k}+\delta^{\prime} \Delta X_{t}+\varepsilon_{t} \\
& \Delta L C D S_{t}=\alpha+\sum_{k=1}^{4} \beta_{\mathrm{k}} \Delta L C D S_{t-k}+\sum_{k=1}^{4} \gamma_{\mathrm{k}} \Delta I C D S_{t-k}+\delta^{\prime} \Delta X_{t}+\varepsilon_{t}
\end{aligned}
$$

where $X$ represents the vector of structural variables such as leverage ratio, stock return volatility, and the risk-free rate. The leverage ratio is computed as the book value of debt and preferred stock divided by the sum of the book value of debt, preferred stock and market value of equity. Implied volatility is used as a proxy for stock return volatility. T-bill rates with onemonth maturity are utilized for the risk-free rate. For each portfolio, leverage ratio and implied volatility are cross-sectionally averaged. 
JDQS
28,3

112

\section{Empirical analysis}

\subsection{Data}

The CDS spread for the US dollar-denominated debt is collected from the Markit database. We select the weekly time series of the CDS spread with five years of maturity and a modified restructure clause for each firm over the sample period from January 2001 to November 2012. The VAR estimation is separately conducted for three periods; we define the pre-crisis period from January 1, 2001 to July 31, 2007, the crisis period from August 1, 2007 to June 30, 2009 and the post-crisis from July 1, 2009 to November 30, 2012. This period definition is determined under consideration of the definitions in the previous literature that addressed similar issues (Galil et al., 2014; Kim et al., 2013; Corò et al., 2013; Tang and Yan, 2017).

Table 1 reports summary statistics of CDS spreads and depth for each liquidity portfolio and for the three periods. As we explained earlier, five groups are constructed based on the liquidity measure, depth. On average, the depth increases for a higher liquidity group. Before the crisis, for example, the number of quotes of CDS sellers (i.e. depth) is 2.2 per day for the most illiquid group, while the most liquid group has 12.8 quotes per day. During the crisis, CDS liquidity does not deteriorate in terms of depth. Rather, the CDS market shrink after the crisis as CDSs are blamed for magnifying the crisis. The depth values in the postcrisis period support this. The depth drops to 7.0 for the most liquid group.

CDS spreads are higher for less liquid groups. Before the crisis, CDS spreads of the ILLIQ group are 225 basis points, while CDS spreads of the LIQ group are only 90 basis points. During the crisis, the negative relation between CDS spreads and depth still remains although the difference reduces. After the crisis, we find that the difference is so marginal that the relationship is no longer monotonically negative. This phenomenon is clearly shown in Figure 1. Overall, the most interesting finding is that LCDS spreads significantly soar through the crisis period.

Figure 1 depicts time series of CDS spreads of two extreme liquidity groups; the red line and blue dotted line correspond to liquid and illiquid groups, respectively. Before the recent crisis, the CDS spread level of illiquid firms was higher than that of liquid firms, on average.

\begin{tabular}{|c|c|c|c|c|c|c|c|c|}
\hline Liquidity portfolio & $\begin{array}{l}\text { CDS spread } \\
\text { Mean }\end{array}$ & Std & Min & $\operatorname{Max}$ & $\begin{array}{l}\text { Depth } \\
\text { Mean }\end{array}$ & Std & Min & $\operatorname{Max}$ \\
\hline \multicolumn{9}{|c|}{ Panel A: Pre-Crisis (Jan 1, 2001 -Jul 31, 2007) } \\
\hline 1 ILLIQ & 225.1 & 83.0 & 87.6 & 569.4 & 2.2 & 0.3 & 2.0 & 3.0 \\
\hline 2 & 189.8 & 74.8 & 84.1 & 472.3 & 3.8 & 0.6 & 2.0 & 5.9 \\
\hline 3 & 146.2 & 57.1 & 64.2 & 372.7 & 5.8 & 1.8 & 3.0 & 10.1 \\
\hline 4 & 91.1 & 46.8 & 31.7 & 248.2 & 8.9 & 3.3 & 3.0 & 16.5 \\
\hline $5 \mathrm{LIQ}$ & 90.0 & 32.5 & 37.1 & 209.8 & 12.8 & 5.3 & 4.0 & 22.9 \\
\hline \multicolumn{9}{|c|}{ Panel B: Crisis (Aug 1, 2007 -Jun 30, 2009) } \\
\hline 1 ILLIQ & 329.9 & 116.2 & 179.3 & 913.3 & 2.0 & 0.0 & 2.0 & 2.0 \\
\hline 2 & 390.0 & 212.6 & 170.2 & 948.1 & 3.4 & 0.4 & 3.0 & 4.0 \\
\hline 3 & 367.0 & 241.2 & 97.6 & 1073.2 & 6.1 & 1.2 & 4.0 & 7.7 \\
\hline 4 & 250.3 & 153.3 & 50.5 & 670.9 & 9.2 & 2.1 & 5.0 & 12.1 \\
\hline $5 \mathrm{LIQ}$ & 261.8 & 128.1 & 94.2 & 627.3 & 12.8 & 3.3 & 6.7 & 18.6 \\
\hline \multicolumn{9}{|c|}{ Panel C: Post-Crisis (Jul 1, 2009 - Nov 30, 2012) } \\
\hline 1 ILLIQ & 267.3 & 71.1 & 152.0 & 488.0 & 2.0 & 0.0 & 2.0 & 2.0 \\
\hline 2 & 230.4 & 47.6 & 149.9 & 458.9 & 3.0 & 0.0 & 3.0 & 3.3 \\
\hline 3 & 220.9 & 52.3 & 121.7 & 342.9 & 4.1 & 0.6 & 3.0 & 5.5 \\
\hline 4 & 216.8 & 53.7 & 122.6 & 416.5 & 5.2 & 0.8 & 3.0 & 7.0 \\
\hline $5 \mathrm{LIQ}$ & 249.8 & 70.3 & 132.3 & 484.0 & 7.0 & 0.8 & 5.2 & 8.7 \\
\hline
\end{tabular}

Table 1.

Descriptive statistics of CDS spreads and depth 


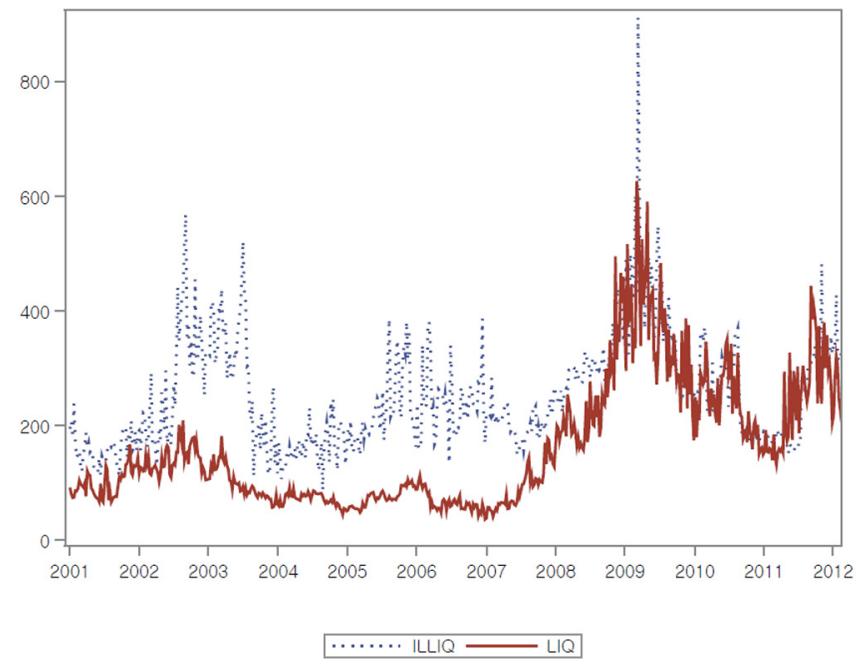

Contagion between liquid and illiquid assets

However, it is noticeable that as the crisis propagates, the CDS spread for liquid firms start to increase so rapidly that it becomes close to the level of illiquid firms, and then, the two groups exhibit similar levels of CDS spreads after 2009. This finding motivates us to investigate the role of liquidity on financial contagion around the crisis period.

\subsection{Granger causality test between the liquid credit default swap and the illiquid credit default swap}

If the time series is unstable with a unit root, the existence of a unit root may cause a problem that the VAR result indicates a significant relation even though there is no relation between the variables. Thus, before performing Granger causality test, we apply the augmented Dickey-Fuller test (Dickey and Fuller, 1979) and Phillips-Perrion test to two variables, changes in LCDS spread and changes in ICDS spread. The representative unit root test, the augmented Dickey-Fuller test, is defined in this study as below:

$$
\begin{aligned}
\Delta L C D S_{t} & =\alpha+\gamma \Delta L C D S_{t-1}+\sum_{k=1}^{4} \rho_{k} \Delta(\Delta L C D S)_{t-k}+\varepsilon_{t} \\
\Delta I C D S_{t} & =\alpha+\gamma \Delta I C D S_{t-1}+\sum_{k=1}^{4} \rho_{k} \Delta(\Delta I C D S)_{t-k}+\varepsilon_{t}
\end{aligned}
$$

Table 2 shows the results of the unit root test that is for checking stationarity. We set up the null hypothesis that each time series have unit root $(\gamma=0)$. If the null hypothesis is not rejected, it is concluded that the time series are not stationary. The numbers in the table represent $t$-values of the $\gamma$ coefficient. We find that all t-values of both in the augmented Dickey-Fuller test and Phillips-Perrion test are substantially significant across all subperiods for two variables. Consequently, we confirm that we can apply the Granger causality test and VAR model to two-time series variables.

Table 3 reports the results of the Granger causality test. For each of the three periods in the full sample, this table presents the $p$-values for the $F$-test that the $\gamma_{k}$ estimates in 
JDQS 28,3

\section{4}

equation (1) or (3) are jointly zero. Panel A shows the $F$-test result of the hypothesis that changes in LCDS spread Granger-causes changes in ICDS and panel B shows that of the hypothesis that changes in ICDS Granger-causes changes in LCDS. Both panels of Table 3 show that, during the pre-crisis period, there is no lead-lag relation between ICDS and $L C D S$. However, panel A of Table 3 shows that, during the crisis period, CDS spreads with high liquidity Granger-cause CDS spreads with low liquidity at the $1 \%$ significance level but this phenomenon disappears after the crisis. This result is the evidence supporting the flight-to-liquidity during the subprime mortgage crisis. On the other hand, panel B of Table 3 shows a noticeable result that, during the post-crisis, CDS spreads with low liquidity Granger-cause CDS spreads with high liquidity after the crisis at the 5\% significance level. This result is somewhat surprising because the previous literature (Hilsche et al., 2015) has provided evidences that liquid assets generally tend to have forecasting power for illiquid assets. Thus we try to take a closer look at the parameters of VAR models.

\subsection{Results of vector autoregression between the liquid credit default swap and the illiquid credit default swap}

Table 4 reports the $\gamma_{k}$ estimates of vector auto-regressive analysis models. Panel A and Panel B show the results based on the VAR model of equations (1) and (3), respectively. Regarding Panel A, during the pre- and post-crisis periods, there is no leading effect by the LCDSs. However, during the crisis period, changes in CDS spread with high liquidity significantly predict changes in CDS spread with low liquidity a week ahead. It is consistent with the Granger causality result of Panel A in Table 3. In addition, the coefficient of changes in LCDS spread at lag 1 is positive (0.56) and significant at the $1 \%$ level, which means that increases in LCDS spreads before one week may move up ICDS spreads at the following week. Thus, it can be interpreted as that negative information of the credit crisis

\begin{tabular}{|c|c|c|c|}
\hline Variable & Before crisis & crisis & After crisis \\
\hline \multicolumn{4}{|c|}{ Panel A: augmented Dickey-Fuller test } \\
\hline$\Delta \mathrm{LCDS}$ & -10.10 **** & $-6.27 * * *$ & -7.97 **** \\
\hline$\Delta \mathrm{ICDS}$ & $-11.02 * * *$ & $-6.75^{* * * *}$ & $-7.11 * * *$ \\
\hline \multicolumn{4}{|c|}{ Panel B: Phillips-Perrion test } \\
\hline$\Delta \mathrm{LCDS}$ & $-26.43 * * *$ & $-20.99 * * *$ & $-27.34 * * *$ \\
\hline$\Delta \mathrm{ICDS}$ & $-25.93 * * *$ & $-17.88 * * *$ & $-20.37 * * * *$ \\
\hline
\end{tabular}

Table 2.

Results of unit root

Note: Significance at the $1 \%, 5 \%$ and $10 \%$ levels is indicated by $* * *, * *$ and *respectively

\begin{tabular}{lccc}
\hline Test statistic & Before crisis & Crisis & After crisis \\
\hline $\begin{array}{l}\text { Panel } \text { A: Test } 1 \\
\text { Chi-square }\end{array}$ & 2.43 & $16.19 * * *$ & \\
$p$-value & $(0.6568)$ & $(0.0028)$ & 4.18 \\
Panel $B$ : Test 3 & & & $(0.3824)$ \\
Chi-square & 1.23 & 4.86 & $10.5 * *$ \\
$p$-value & $(0.8739)$ & $(0.3023)$ & $(0.0328)$ \\
Note: Significance at the $1 \%, 5 \%$ and $10 \%$ levels is indicated by ***,** and * respectively & \\
\hline
\end{tabular}




\begin{tabular}{|c|c|c|c|c|c|c|}
\hline Period & Variable & Estimate & Standard error & t-stat. & $p$-value & $\begin{array}{l}\text { Contagion } \\
\text { hetween linuid }\end{array}$ \\
\hline \multicolumn{6}{|c|}{ Panel A: $\mathrm{H} 2 . L C D S \rightarrow I C D S$} & \multirow{9}{*}{$\begin{array}{r}\text { and illiquid } \\
\text { assets }\end{array}$} \\
\hline \multirow[t]{4}{*}{ Before crisis } & $\triangle L C D S(-1)$ & 1.5003 & 1.9832 & 0.76 & 0.4508 & \\
\hline & $\triangle L C D S(-2)$ & -1.0445 & 2.0542 & -0.51 & 0.6120 & \\
\hline & $\triangle L C D S(-3)$ & 0.2973 & 2.0691 & 0.14 & 0.8860 & \\
\hline & $\triangle L C D S(-4)$ & 2.1406 & 2.0063 & 1.07 & 0.2882 & \\
\hline \multirow[t]{4}{*}{ Crisis } & \multirow{4}{*}{$\begin{array}{l}\Delta L C D S(-1) \\
\Delta L C D S(-2) \\
\Delta L C D S(-3) \\
\Delta L C D S(-4)\end{array}$} & \multirow{4}{*}{$\begin{array}{r}0.5914 \\
0.0419 \\
-0.2237 \\
-0.2321\end{array}$} & \multirow{4}{*}{$\begin{array}{l}0.1998 \\
0.2678 \\
0.2733 \\
0.2286\end{array}$} & \multirow{4}{*}{$\begin{array}{r}2.96 \\
0.16 \\
-0.82 \\
-1.02\end{array}$} & \multirow{4}{*}{$\begin{array}{l}0.0040 \\
0.8760 \\
0.4153 \\
0.3127\end{array}$} & \\
\hline & & & & & & \\
\hline & & & & & & \\
\hline & & & & & & \\
\hline \multirow{4}{*}{ After crisis } & $\triangle L C D S(-1)$ & 0.0932 & 0.0987 & 0.94 & 0.3465 & \\
\hline & $\triangle L C D S(-2)$ & 0.1693 & 0.1155 & 1.47 & 0.1448 & \\
\hline & $\triangle L C D S(-3)$ & -0.0057 & 0.1136 & -0.05 & 0.9602 & \\
\hline & $\triangle L C D S(-4)$ & 0.0419 & 0.0947 & 0.44 & 0.6588 & \\
\hline \multicolumn{7}{|c|}{ Panel B: H4. ICDS $\rightarrow$ LCDS } \\
\hline \multirow[t]{4}{*}{ Before crisis } & $\Delta \operatorname{ICDS}(-1)$ & -0.0008 & 0.0043 & -0.20 & 0.8456 & \\
\hline & $\triangle I C D S(-2)$ & 0.0034 & 0.0043 & 0.79 & 0.4323 & \\
\hline & $\triangle I C D S(-3)$ & 0.0013 & 0.0043 & 0.31 & 0.7548 & \\
\hline & $\triangle I C D S(-4)$ & -0.0019 & 0.0043 & -0.44 & 0.6641 & \\
\hline \multirow[t]{4}{*}{ Crisis } & $\triangle I C D S(-1)$ & -0.0031 & 0.0683 & -0.05 & 0.9636 & \\
\hline & $\triangle I C D S(-2)$ & -0.0753 & 0.0842 & -0.90 & 0.3731 & \\
\hline & $\triangle I C D S(-3)$ & -0.0006 & 0.0843 & -0.01 & 0.9940 & \\
\hline & $\triangle I C D S(-4)$ & -0.0942 & 0.0655 & -1.44 & 0.1538 & \\
\hline \multirow[t]{4}{*}{ After crisis } & $\triangle I C D S(-1)$ & 0.0934 & 0.0592 & 1.58 & 0.1165 & \multirow{4}{*}{$\begin{array}{r}\text { Table } 4 . \\
\text { Results of vector } \\
\text { auto-regressive } \\
\text { analysis }\end{array}$} \\
\hline & $\triangle I C D S(-2)$ & 0.1310 & 0.0709 & 1.85 & 0.0665 & \\
\hline & $\triangle I C D S(-3)$ & 0.2057 & 0.0696 & 2.96 & 0.0036 & \\
\hline & $\triangle I C D S(-4)$ & 0.0503 & 0.0590 & 0.85 & 0.3954 & \\
\hline
\end{tabular}

was incorporated first into the LCDSs because of the flight-to-liquidity and subsequently propagated into the ICDSs during the recent crisis period.

Panel B shows that, during the pre-crisis and crisis periods, there is no evidence of the leading role of the ICDSs. On the other hand, during the post-crisis period, changes in the ICDS spread have significant forecasting power for changes in the LCDS spread two to three weeks ahead. It is also consistent with the Granger causality result of Panel $\mathrm{B}$ in Table 3. Moreover, the coefficient of changes in the ICDS spread at lag 2 and lag 3 are (about 0.13 and 0.21 ) at the $10 \%$ and $1 \%$ significance levels, respectively. This result implies that variations of the LCDS spread are impacted by changes in the ICDS spreads during the post-crisis period.

Differently from that, in 2007, the more liquid stock and bond markets were led by the illiquid asset, ABX index market, as reported in Longstaff (2010), our result suggests that, during the post-crisis period, not in 2007, the less LCDSs' predictive power for the more-LCDSs has grown substantially. However, we also garner evidence that the contagion effect is related to the liquidity (Longstaff, 2010); the illiquidity-induced credit risk information from CDSs of the distressed firms spills over into CDSs of relatively liquid firms after the crisis period.

Table 5 reports the $\gamma_{k}$ estimate of vector auto-regressive analysis models after controlling for structural variables. Panel A and Panel B show the results based on the VAR model of equations (4) and (5), respectively. We find that the above results are robust 


\begin{tabular}{|c|c|c|c|c|c|c|}
\hline \multirow{2}{*}{$\begin{array}{l}\text { JDQS } \\
28,3\end{array}$} & Period & Variable & Estimate & Std. error & $t$-stat. & $p$-value \\
\hline & $\begin{array}{l}\text { Panel A: H4. } \\
\text { Before crisis }\end{array}$ & $\begin{array}{l}I C D S \\
\Delta L C D S(-1) \\
\Delta L C D S(-2) \\
\Delta L C D S(-3) \\
\Delta L C D S(-4)\end{array}$ & $\begin{array}{r}1.51528 \\
-1.01058 \\
0.57861 \\
2.36531\end{array}$ & $\begin{array}{l}2.00889 \\
2.10316 \\
2.10787 \\
2.03651\end{array}$ & $\begin{array}{r}0.75 \\
-0.48 \\
0.27 \\
1.16\end{array}$ & $\begin{array}{l}0.4522 \\
0.6318 \\
0.7842 \\
0.2478\end{array}$ \\
\hline \multirow{4}{*}{116} & Crisis & $\begin{array}{l}\Delta L C D S(-1) \\
\Delta L C D S(-2) \\
\Delta L C D S(-3) \\
\Delta L C D S(-4)\end{array}$ & $\begin{array}{r}0.52960 \\
0.01306 \\
-0.23584 \\
-0.31701\end{array}$ & $\begin{array}{l}0.18007 \\
0.23959 \\
0.24577 \\
0.20653\end{array}$ & $\begin{array}{r}2.94 \\
0.05 \\
-0.96 \\
-1.53\end{array}$ & $\begin{array}{l}0.0042 \\
0.9567 \\
0.3400 \\
0.1286\end{array}$ \\
\hline & After crisis & $\begin{array}{l}\Delta L C D S(-1) \\
\Delta L C D S(-2) \\
\Delta L C D S(-3) \\
\Delta L C D S(-4)\end{array}$ & $\begin{array}{r}0.08716 \\
0.14118 \\
-0.02338 \\
0.03696\end{array}$ & $\begin{array}{l}0.09802 \\
0.11503 \\
0.11329 \\
0.09339\end{array}$ & $\begin{array}{r}0.89 \\
1.23 \\
-0.21 \\
0.40\end{array}$ & $\begin{array}{l}0.3752 \\
0.2215 \\
0.8368 \\
0.6928\end{array}$ \\
\hline & $\begin{array}{l}\text { Panel B: H6. } \\
\text { Before crisis }\end{array}$ & $\begin{array}{l}L C D S \\
\triangle I C D S(-1) \\
\Delta I C D S(-2) \\
\Delta I C D S(-3) \\
\triangle I C D S(-4)\end{array}$ & $\begin{array}{r}0.00033 \\
0.00537 \\
0.00107 \\
-0.00046\end{array}$ & $\begin{array}{l}0.00376 \\
0.00373 \\
0.00376 \\
0.00371\end{array}$ & $\begin{array}{r}0.09 \\
1.44 \\
0.28 \\
-0.12\end{array}$ & $\begin{array}{l}0.9310 \\
0.1523 \\
0.7766 \\
0.9009\end{array}$ \\
\hline & Crisis & $\begin{array}{l}\triangle I C D S(-1) \\
\triangle I C D S(-2) \\
\triangle I C D S(-3) \\
\triangle I C D S(-4)\end{array}$ & $\begin{array}{r}-0.02824 \\
-0.07710 \\
0.02910 \\
-0.03983\end{array}$ & $\begin{array}{l}0.05570 \\
0.06952 \\
0.07145 \\
0.05368\end{array}$ & $\begin{array}{r}-0.51 \\
-1.11 \\
0.41 \\
-0.74\end{array}$ & $\begin{array}{l}0.6134 \\
0.2706 \\
0.6849 \\
0.4602\end{array}$ \\
\hline $\begin{array}{l}\text { Results of vector } \\
\text { auto-regressive } \\
\text { analysis with control } \\
\text { variables }\end{array}$ & After crisis & $\begin{array}{l}\triangle I C D S(-1) \\
\triangle I C D S(-2) \\
\Delta I C D S(-3) \\
\Delta I C D S(-4)\end{array}$ & $\begin{array}{l}0.06670 \\
0.11895 \\
0.18002 \\
0.06516\end{array}$ & $\begin{array}{l}0.05688 \\
0.06870 \\
0.06760 \\
0.05653\end{array}$ & $\begin{array}{l}1.17 \\
1.73 \\
2.66 \\
1.15\end{array}$ & $\begin{array}{l}0.2427 \\
0.0853 \\
0.0085 \\
0.2508\end{array}$ \\
\hline
\end{tabular}

because the magnitude of coefficients of lead-lag and their significances are similar to those in Table 4. In Panel A, during the pre- and post-crisis periods, changes in the LCDS spread have no forecasting ability. However, during the crisis period, changes in the LCDS spread leads changes in the ICDS spread a week ahead. Moreover, the coefficient of changes in the LCDS spread at lag 1 is positive (0.53) and significant at the $1 \%$ level.

From Panel B of Table 5, we discover that, during the pre-crisis and crisis periods, there is no information spillover from the ICDSs. On the other hand, during the post-crisis period, changes in the ICDS spread predict changes in the LCDS spread two to three weeks ahead. In addition, the coefficients of changes in the ICDS spread at lag 2 and lag 3 are significantly positive (about 0.12 and 0.18 ) at the $10 \%$ and $1 \%$ levels, respectively. This result suggests that the lead-lag relationship is not impacted by structural variables. Hence, we conclude that contagion effects come from the part of changes in CDS spread that cannot be explained by default variables.

\section{Alternative test for contagion}

In the literature on financial contagion, because Engle (2002) proposed the DCC model, many studies have used the DCC model to examine if there exists a contagion effect between two assets or markets. For example, Celik (2012) confirms the contagion effect among emerging stock markets during the recent crisis period by showing that the average DCC significantly 
increases during the crisis. Naoui et al. (2010) also use the DCC method, finding evidence of financial contagion among developed and emerging countries after the subprime crisis. Such papers using the DCC model accept one definition of financial contagion: a contagion results in an excessive increase in correlation between two assets during crises. Once we estimate the time series of DCC, we can test if the DCC between the LCDSs and ICDSs increases during the crisis period, compared with the other periods.

We first describe the DCC model and then discuss how to apply it to a contagion test with empirical results. The DCC model extends the constant conditional correlation of Bollerslev (1990) by putting different weights on conditional correlations over time. As a result, the method allows us to estimate a dynamically weighted time-varying correlation that reflects all information up-to-date. Economically, the model typically assumes that error terms are correlated and the conditional correlation follows the generalized autoregressive conditional heteroscedasticity $(\mathrm{GARCH})$ dynamics. The DCC model with a GARCH assumption is called the DCC-GARCH model. Specifically, we use the DCC-GARCH(1,1). The model specification used by our study is as follows [2].

We assume a two-dimensional DCC-GARCH(1,1) model. That is:

$$
\mathrm{y}_{\mathrm{t}}=m+\varepsilon_{\mathrm{t}}, \quad \text { where } \varepsilon_{\mathrm{t}} \sim N\left(0, H_{t}\right)
$$

where $y_{t}$ is the CDS spread vector, $m$ is the unconditional mean vector, and $\varepsilon_{t}$ is a heteroscedastic noise vector with $\operatorname{GARCH}(1,1)$ assumption. Thus, the conditional covariance matrix $H_{t}=\left[\begin{array}{ll}h_{11, t} & h_{12, t} \\ h_{21, t} & h_{22, t}\end{array}\right]$ evolves as follows:

$$
h_{t}=w+\alpha \varepsilon_{t-1}^{2}+\beta h_{t-1}
$$

where $w, \alpha$ and $\beta$ are unconditional mean of covariance and $\operatorname{GARCH}(1,1)$ parameters, respectively. We omit the subscripts for all parameters of the $(i, j)$ th component of $H_{t}$ for simplicity. Estimating three DCC-GARCH parameters $(w, \alpha$ and $\beta)$ for $h_{11, t}, h_{22, t}$ and $h_{12, t}$ results in nine parameter estimates. Following Engle (2002), the parameters and the time series of the conditional covariance matrix $H_{t}$ are estimated using the two-stage maximum log-likelihood (ML) method. We first maximize the respective log-likelihood of univariate $\mathrm{GARCH}(1,1)$ processes. Once the parameters are related to univariate GARCH processes, we maximize the log-likelihood of DCC-GARCH with the assumption that the first stage ML estimates are the optimal points in the second stage. By doing so, we can reduce the dimension to search for the optimum. The formula of the log-likelihood with a normality assumption is given in Engle (2002) and Celik (2012).

Table 6 reports the estimation result of DCC-GARCH(1,1) for ICDS and LCDS. Corresponding standard errors of the estimates are included in parentheses. Small standard errors prove that the GARCH parameters for the respective univariate processes and the covariance process (i.e. $\alpha$ 's and $\beta$ 's) are estimated with a high significance. We note that the persistence parameter $\beta$ is relatively high, implying that the covariance (or correlation) persists with a degree of 0.725 .

\begin{tabular}{lccc}
\hline Parameters & ICDS & LCDS & Covariance \\
\hline$w$ & $0.042(0.021)$ & $0.025(0.012)$ & $0.288(0.234)$ \\
$\alpha$ & $0.435(0.084)$ & $0.336(0.035)$ & $0.258(0.070)$ \\
$\beta$ & $0.532(0.090)$ & $0.635(0.038)$ & $0.725(0.083)$
\end{tabular}

Contagion between liquid and illiquid

assets \\ 117}

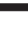

(1) 
JDQS 28,3

\section{8}

The basic idea of the contagion test using the DCC model such as Celik (2012) is intuitive. Based on a definition of contagion that asset prices are more correlated in excess of their fundamental relations when contagion exists, the contagion test using the DCC model is to examine if the DCC varies over time and if it excessively increases during a period where the existence of contagion is suspected. Therefore, the null hypothesis of the contagion test is:

$$
\left.H_{0}: \quad \rho \text { (Before or after } \text { crisis }\right)=\rho \quad \text { (Crisis) }
$$

We can test the null hypothesis by comparing the average of DCC values over time relative to their standard errors. With the estimates in Table 6, we compute the time series of dynamic conditional covariance in (9) and DCC, $\rho_{t}$, as below:

$$
\rho_{t}=\frac{h_{12, t}}{\sqrt{h_{11, t} h_{22, t}}}
$$

Under the independence assumption, the associated $t$-statistic is given by:

$$
t=\frac{\bar{\rho}_{C}-\bar{\rho}_{N}}{\sqrt{\frac{\sigma\left(\rho_{t_{c}}\right)}{T_{C}}+\frac{\sigma\left(\rho_{\left.t_{N}\right)}\right)}{T_{N}}}}
$$

where $\bar{\rho}$ and $\sigma\left(\rho_{t}\right)$ are the mean and standard deviation of DCCs, respectively and $T$ is the number of weeks during a period. The subscripts $C$ and $N$ denote the crisis and non-crisis periods, respectively; the noncrisis period is either before-crisis period or after-crisis period. The two-tail $t$-test is conducted with a degree of freedom $(D F)$ :

$$
D F=\frac{\left[\frac{\sigma^{2}\left(\rho_{t_{c}}\right)}{T_{C}}+\frac{\sigma^{2}\left(\rho_{t_{c}}\right)}{T_{C}}\right]^{2}}{\frac{\sigma^{4}\left(\rho_{t_{c}}\right)}{T_{C}^{2}\left(T_{C}-1\right)}+\frac{\sigma^{4}\left(\rho_{t_{N}}\right)}{T_{N}^{2}\left(T_{N}-1\right)}}
$$

The result for the $t$-test is reported in Table 7. Panel A of Table 7 shows that the average DCC is higher than the other periods. Specifically, the average DCC is 0.676 during the crisis, while it is 0.470 and 0.312 before and after the crisis, respectively. It seems that there was a contagion effect between LCDSs and ICDSs that led to an increase in DCC on average. However, it is necessary to test if the increment is statistically significant.

Panel B of Table 7 conducts a more rigorous test in a statistical sense. The $t$-test is conducted with the null hypothesis that there is no difference between the mean values of DCCs for two

\begin{tabular}{lcll}
\hline Contagion between LCDSs and ICDSs & Before crisis & Crisis & After crisis \\
\hline Panel A: summary statistics of $\rho_{\mathrm{t}}$ & & & \\
Mean & 0.470 & 0.676 & 0.312 \\
Std. dev & 0.566 & 0.318 & 0.524 \\
Panel B: $\mathrm{t}$-test for contagion & & & \\
$\mathrm{H}_{O}$ & $t$ stat & DF & $p$-value \\
$\rho($ before crisis $)=\rho($ crisis $)$ & 4.27 & 295.73 & $2.66 \times 10^{-5}$ \\
$\rho($ after crisis $)=\rho($ crisis $)$ & 7.80 & 273.58 & $1.30 \times 10^{-13}$ \\
\hline
\end{tabular}

$\rho($ before crisis $)=\rho($ crisis $)$
$\rho($ after crisis $)=\rho($ crisis $)$

4.27

273.58
Table 7.

Contagion test by DCC-GARCH $(1,1)$ 
periods: crisis vs. noncrisis. The average DCC increases during the crisis, compared with that in the pre-crisis period. The associated $t$ statistic for this test using (12) is 4.27 , and the $p$-value of a $t$-distribution with a DF of 295.73 is $2.66 \times 10^{-5}$. Thus, we can conclude the difference is statistically significant at the $1 \%$ level. Similarly, the test between the crisis and post-crisis periods results in a $t$-statistic of 7.80 and a $p$-value of $1.30 \times 10^{-13}$. This result is highly significant. Based on these findings, we can conclude that there was a contagion between LCDSs and ICDSs during the crisis. Even though the DCC model cannot tell the direction or cause of the contagion, we confirm that our main finding is robust, using the DCC-GARCH approach.

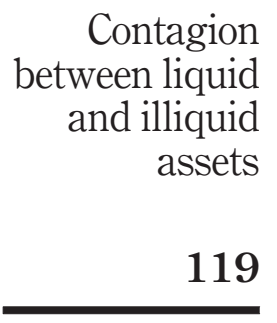

\section{Conclusion}

This study explores the role of liquidity on the lead/lag relationship between assets in the CDS market around the subprime mortgage crisis period. While previous researches generally focused on the contagions between countries or between the financial assets market, there is a little study on contagion within an asset class. This study fills this gap and contributes the literature by exploring the contagion effect within the CDSs market. In particular, we focus on examining whether there exists the flight-to-liquidity phenomenon and default contagion between LCDSs and ICDSs when CDSs belong to the distressed assets because of the subprime mortgage defaults.

Our main empirical results are summarized as follows. First, we find that the LCDSs have developed significant predictive power for the ICDSs a week ahead during the crisis period but there is no leading effect by LCDSs during the pre- and post-crisis periods. In addition, we show that changes in CDS spreads with high liquidity Granger-cause changes in CDS spreads with low liquidity at the $1 \%$ significance level, whereas this phenomenon disappears after the crisis. This finding can be interpreted as negative information of the credit crisis was incorporated first into the LCDSs because of the flight-to-liquidity and subsequently propagated into the ICDSs during the recent crisis period.

Second, there is no evidence of the leading role of the ICDSs during the pre-crisis and crisis periods. On the other hand, changes in ICDS spread have significant forecasting power for changes in LCDS spread two to three weeks ahead during the post-crisis period. Moreover, CDS spreads with low liquidity and Granger-caused CDS spreads with high liquidity at the $5 \%$ significance level after the crisis. Differently from Longstaff (2010)'s finding that, in 2007, the market of an illiquid asset, $\mathrm{CDO}$, forecasted the future movements of the more liquid stock and bond markets, our result suggests that, during the post-crisis period, not in 2007, the less LCDSs' predictive power for the more-LCDSs has grown substantially. However, our result supports evidence that the contagion effect is related to the liquidity, consistent with Longstaff (2010); the illiquidity-induced credit risk information from CDSs of the distressed firms spills over into CDSs of relatively liquid firms after the crisis period. In addition, it is consistent with the Rösch and Kaserer (2013)'s conclusion of that financial contagion was driven by market liquidity.

Finally, the above results are robust after controlling for structural variables. This suggests that the lead-lag relationship is not impacted by structural variables and contagion effects come from some portion of changes in CDS spread that cannot be explained by theoretical variables.

Inferring from these results, we argue that the forecasting ability of LCDS spreads for illiquid ones during the crisis period is associated with the flight-to-liquidity and that the forecasting ability during the post-crisis period is associated with default contagion through liquidity and that negative credit information from CDS spread of distressed and illiquid firms spills over into CDS spread of relatively liquid firms during the post-crisis period. 
1. Akaike information criterion suggests four weeks as the optimal lag for this model.

2. The specification of general models is given in Engle (2002).

\section{References}

Aloui, R., Safouane Ben Aïssa, M. and Nguyen, D.K. (2011), "Global financial crisis, extreme interdependences, and contagion effects: the role of economic structure?", Journal of Banking and Finance, Vol. 35 No. 1, pp. 130-141. doi: 10.1016/j.jbankfin.2010.07.021.

Bae, K. Karolyi, G.A. and Stulz, R. (2003), "A new approach to measuring financial market contagion, forthcoming in the review of financial studies", Review of Financial Studies, Vol. 16, pp. 717-764.

Berndt, A. Douglas, R. Duffie, D. Ferguson, M. and Schranz, D. (2008), "Measuring default risk Premia from default swap rates and EDFs", Tepper School of Business, p. 49.

Bollerslev, T. (1990), "Modelling the coherence in short-run nominal exchange rates: a multivariate generalized ARCH model", The Review of Economics and Statistics, Vol. 72 No. 3, pp. 498-505.

Bongaerts, D., De Jong, F. and Driessen, J. (2011), "Derivative pricing with liquidity risk: theory and evidence from the credit default swap market", The Journal of Finance, Vol. 66 No. 1, pp. 203-240. doi: 10.1111/ j.1540-6261.2010.01630.x.

Cellk, S. (2012), "The more contagion effect on emerging markets: the evidence of DCC-GARCH model", Economic Modelling, Vol. 29 No. 5, pp. 1946-1959. doi: 10.1016/j.econmod.2012.06.011.

Cheng, K., Lu, F. and Yang, X. (2012), "Copula contagion index and its efficiency", Applied Financial Economics, Vol. 22 No. 12, pp. 989-1002. doi: 10.1080/09603107.2011.633889.

Cheung, L., Tam, C.-S. and Szeto, J. (2009), "Contagion of financial crises: a literature review of theoretical and empirical frameworks", Hong Kong Monetary Authority Research Paper 02.

Cifuentes, R., Ferrucci, G. and Shin, H.S. (2005), "Liquidity risk and contagion”, Journal of the European Economic Association, Vol. 3 Nos 2/3, pp. 556-566. doi: 10.1162/jeea.2005.3.2-3.556.

Corò, F., Dufour, A. and Varotto, S. (2013), "Credit and liquidity components of corporate CDS spreads", Journal of Banking and Finance, Vol. 37 No. 12, pp. 5511-5525. doi: 10.1016/j.jbankfin.2013.07.010.

Di Cesare, A. and Guazzarotti, G. (2010), "An analysis of the determinants of credit default swap spread changes before and during the subprime financial turmoil", SSRN Scholarly Paper ID 1670045, Social Science Research Network, Rochester, New York, NY, available at: https:/papers.ssrn.com/abstract=1670045.

Dickey, D.A. and Fuller, W.A. (1979), "Distribution of the estimators for autoregressive time series with a unit root", Journal of the American Statistical Association, Vol. 74 No. 366a, pp. 427-431.

Dieckmann, S. and Plank, T. (2012), "Default risk of advanced economies: an empirical analysis of credit default swaps during the financial crisis", Review of Finance, Vol. 16 No. 4, pp. 903-934. doi: 10.1093/rof/rfr015.

Dornbusch, R., Park, Y.C. and Claessens, S. (2000), "Contagion: how it spreads and how it can be stopped”, The World Bank Research Observer, Vol. 15 No. 2, pp. 177-197.

Doshi, H., Ericsson, J., Jacobs, K. and Turnbull, S.M. (2013), "Pricing credit default swaps with observable covariates”, Review of Financial Studies, Vol. 26 No. 8, pp. 2049-2094.

Eichengreen, B. Rose, A.K. and Wyplosz, C. (1996), "Contagious currency crises", National bureau of economic research.

Engle, R. (2002), "Dynamic conditional correlation", Journal of Business and Economic Statistics, Vol. 20 No. 3, pp. 339-350. doi: $10.1198 / 073500102288618487$.

Eom, Y.H., Helwege, J. and Huang, J.-Z. (2004), "Structural models of corporate bond pricing: an empirical analysis", Review of Financial Studies, Vol. 17 No. 2, pp. 499-544. doi: 10.1093/rfs/hhg053.

Ericsson, J., Jacobs, K. and Oviedo, R. (2009), “The determinants of credit default swap premia”, Journal of Financial and Quantitative Analysis, Vol. 44 No. 1, pp. 109-132. 
Galil, K., Shapir, O.M., Amiram, D. and Ben-Zion, U. (2014), “The determinants of CDS spreads”, Journal of Banking and Finance, Vol. 41, pp. 271-282. doi: 10.1016/j.jbankfin.2013.12.005.

Greatrex, C.A. (2008), "Credit default swap market determinants", The Journal of Fixed Income, Vol. 18 No. 3, pp. 18-32. doi: 10.3905/JFI.2009.18.3.018.

Guo, F., Chen, C.R. and Huang, Y.S. (2011), "Markets contagion during financial crisis: a regimeswitching approach", International Review of Economics and Finance, Special Issue: The Emerging Global Financial Architecture and Exchange Rate Regimes in a Volatile World, Vol. 20 No. 1, pp. 95-109. doi: 10.1016/j.iref.2010.07.009.

Contagion between liquid and illiquid assets

Han, B. and Kumar, A. (2013), "Speculative retail trading and asset prices", Journal of Financial and Quantitative Analysis, Vol. 48 No. 2, pp. 377-404. doi: 10.1017/S0022109013000100.

Hegde, S. and Paliwal, R. (2011), "Financial contagion and market liquidity: evidence from the Asian crisis”, WCOB Faculty Publications, July, available at: https://digitalcommons. sacredheart.edu/wcob_fac/3

Hilscher, J., Pollet, J.M. and Wilson, M. (2015), "Are credit default swaps a sideshow? Evidence that information flows from equity to CDS markets", Journal of Financial and Quantitative Analysis, Vol. 50 No. 3, pp. 543-567. doi: 10.1017/S0022109015000228.

Jacoby, G. Jiang, G.J. and Theocharides, G. (2009), "Cross-market liquidity shocks: evidence from the CDS, corporate bond, and equity markets", University of Arizona, Unpublished Working Paper.

Kim, J., Park, Y.J. and Ryu, D. (2016), "Hawkes-diffusion process and the conditional probability of defaults in the eurozone", Physica A: Statistical Mechanics and Its Applications, Vol. 449, pp. 301-310. doi: 10.1016/j.physa.2015.12.087.

Kim, T.S., Park, J.W. and Park, Y.J. (2017), "Macroeconomic conditions and credit default swap spread changes", Journal of Futures Markets, Vol. 37 No. 8, pp. 766-802. doi: 10.1002/fut.21836.

Kim, T.S., Park, Y.J. and Noh, J. (2013), "The linkage between the options and credit default swap markets during the subprime mortgage crisis", Journal of Futures Markets, Vol. 33 No. 6, pp. 518-554. doi: 10.1002/fut.21595.

Longstaff, F.A. (2002), “The flight-to-liquidity premium in US treasury bond prices”, National bureau of economic research.

Longstaff, F.A. (2010), "The subprime credit crisis and contagion in financial markets", Journal of Financial Economics, Vol. 97 No. 3, pp. 436-450.

Merton, R.C. (1974), "On the pricing of corporate debt: the risk structure of interest rates*", The Journal of Finance, Vol. 29 No. 2, pp. 449-470.

Naoui, K., Liouane, N. and Brahim, S. (2010), "A dynamic conditional correlation analysis of financial contagion: the case of the subprime credit crisis", International Journal of Economics and Finance, Vol. 2 No. 3. doi: 10.5539/ijef.v2n3p85.

Pontines, V. and Siregar, R.Y. (2009), "Tranquil and crisis windows, heteroscedasticity, and contagion measurement: MS-VAR application of the DCC procedure", Applied Financial Economics, Vol. 19 No. 9, pp. 745-752. doi: 10.1080/09603100802167239.

Rodriguez, J.C. (2007), "Measuring financial contagion: a copula approach", Journal of Empirical Finance, Vol. 14 No. 3, pp. 401-423. doi: 10.1016/j.jempfin.2006.07.002.

Rösch, C.G. and Kaserer, C. (2013), "Market liquidity in the financial crisis: the role of liquidity commonality and flight-to-quality", Journal of Banking and Finance, Vol. 37 No. 7, pp. 2284-2302.

Stulz, R.M. (2010), "Credit default swaps and the credit crisis", Joumal of Economic Perspectives, Vol. 24 No. 1, pp. 73-92. doi: $10.1257 /$ jep.24.1.73.

Tang, D.Y. and Yan, H. (2010), "Market conditions, default risk and credit spreads", Journal of Banking and Finance, Interaction of Market and Credit Risk, Vol. 34 No. 4, pp. 743-753. doi: 10.1016/j. jbankfin.2009.05.018. 
JDQS 28,3

Tang, D.Y. and Yan, H. (2017), "Understanding transactions prices in the credit default swaps market", Journal of Financial Markets, Vol. 32, pp. 1-27. doi: 10.1016/j.finmar.2016.09.005.

Terzi, N. and Uluçay, K. (2011), "The role of credit default swaps on financial market stability", Procedia - Social and Behavioral Sciences, the Proceedings of 7th International Strategic Management Conference, Vol. 24, pp. 983-990. doi: 10.1016/j.sbspro.2011.09.066.

Vayanos, D. (2004), "Flight to quality, flight to liquidity, and the pricing of risk", National Bureau of Economic Research.

\section{Corresponding author}

Yuen Jung Park can be contacted at: yjpark@hallym.ac.kr

For instructions on how to order reprints of this article, please visit our website: 